\title{
New insights about barium biomineralization in Spirogyra
}

\author{
NATERCIA BARBOSA GONÇALVES, OSCAR URQUIDI \\ GANDARILLAS, TAKUJI ADACHI AND MONTSERRAT \\ FILELLA
}

University of Geneva

Presenting Author: natercia.barbosa@etu.unige.ch

Recognizable for its helical chloroplast's arrangement, Spirogyra is a multicellular green alga which has been widely used as a model organism to study the algal system. Reproduction, mitosis and organelle transport, have been investigated thanks to particular transparency of Spirogyra cells, making it an ideal microscopical object [1]. Yet, a rather incredible discovery was quickly forgotten. In 1957, Kreger identified barite microcrystals in Spirogyra cells by X-ray diffraction and suggested that the particles moving in Brownian motion, visible under an optical microscope, could match the barite signals as detected by the XRD [2]. Thirty years later, Grolig describes these particles as "small vesicles of high refraction"..." most of the time showed rapid Brownian motion..." and which "rarely moved on the tracks with the other particles and then only for short distances" [3].

Although barite biomineralization is well known for its fellow unicellular green algae, Closterium [4] and Micrasterias [5], its nucleation mechanism and function remain largely unknown. Using a laser tweezer Raman microspectroscopy in vivo, we succeeded in proving the original hypothesis of Kreger that the mobile particles in the cells observed under optical microscope are in fact the barite crystallites. Barite microcrystals are not fixed within the cells but are diffusing, and this character is common to the genus Spirogyra. By tracking the diffusive motion of barite crystallites, we further investigated the details of the physical and chemical properties of cytoplasm. This new information obtained in vivo could be a key step toward understanding the nucleation process of barite in Spirogyra and finding the answer to the fundamental question of how these crystals form within Spirogyra at the first place.

[1] Johansen (1940), McGraw-Hill, New York and London.

[2] Kreger \& Boeré (1969), Acta Botanica Neerlandica 18, 143-151.

[3] Grolig (1990), Protoplasma 155, 29-42.

[4] Brook, Fotheringham, Bradly \& Jenkins (1980), British Phycological Journal 15, 261-264.

[5] Meindl (1984), Phyton 24, 273-276. 